\title{
PENGEMBANGAN MEDIA PEMBELAJARAN BERBASIS VISUAL BASIC APPLICATION POWERPOINT PADA MATERI SISTEM PERSAMAAN LINEAR DUA VARIABEL
}

\author{
Dea Rosmayanti ${ }^{1}$, Luvy Sylviana Zanthy ${ }^{2}$ \\ ${ }^{1,2}$ Program Studi Pendidikan Matematika IKIP Siliwangi, Jln Terusan Jenderal Sudirman. Cimahi \\ ${ }^{1}$ dea.rosmayanti@gmail.com, ${ }^{2}$ lszanthy@gmail.com
}

\begin{abstract}
This research is development research with the aims to develop VBA Powerpoint based learning media on SPLDV material. Samples for this research are taken from one of junior high school in Bandung. This study refers to the ADDIE development, namely: Analysis (Analysis Phase), Design (Design Phase), Development (Development Phase), Implementation (Implementation Phase), and Evaluation (Evaluation Phase). The instrument which is used to obtain research material is in the form of assessment sheets for material experts, media experts, teachers and students. Based on the analysis the following result were obtained, material experts stated that the product was very valid with score 3.64, media experts stated that the product was valid with score 3.06. While the results of teacher responses can be concluded that the product is very valid with score 3.50 and from the results of student responses can be concluded that the product is valid with score 3.18.
\end{abstract}

Keywords: learning media, SPLDV, powerpoint

\begin{abstract}
Abstrak
Penelitian ini adalah penelitian pengembangan yang bertujuan mengembangkan Media pembelajaran berbasis VBA MS.Powerpoint pada materi SPLDV. Sample dari penelitian ini adalah siswa kelas VIII disalah satu SMP Kota Bandung. Penelitian ini dilaksanakan dengan mengacu pada model pengembangan ADDIE, yaitu Analysis (Tahap Analisis), Design (Tahap Desain), Development (Tahap Pengembangan), Implementation (Tahap Penerapan), dan Evaluation (Tahap Evaluasi). Instrumen yang dipakai berupa lembar penilaian yang diberikan kepada dua orang ahli materi, dua orang ahli media, dua orang guru dan beberapa perwakilan siswa. Berdasarkan hasil analisis didapat hasil sebagai berikut, ahli materi menyatakan produk sangat valid dengan skor sebesar 3.64, ahli media menyatakan produk valid dengan skor 3.06. Sedangkan dari hasil respon guru menunjukan bahwa produk sangat valid dengan skor 3.50 dan dari hasil respon siswa menunjukan bahwa produk valid dengan skor 3.18.
\end{abstract}

Kata Kunci: Media Pembelajaran, SPLDV, Powerpoint

How to cite: Rosmayanti, DR., Zanthy, LS. (2019). Pengembangan Media Pembelajaran Berbasis Visual Basic Application Powerpoint Pada Materi Sistem Persamaan Linear Dua Variabel. JPMI - Jurnal Pembelajaran Matematika Inovatif, 2 (6), 401-414.

\section{PENDAHULUAN}

Kemajuan teknologi masa kini berkembang kencang sehingga kualitas SDM dituntut untuk berkembang dan meningkat. Kemajuan teknologi bagi suatu negara dengan didampingi oleh SDM yang kompeten dapat mempengaruhi perkembangan kemajuan suatu negara. Perkembangan teknologi saat ini tentunya perlu diimbangi dengan pengetahuan dan keterampilan SDM pada bidang keahliannya masing-masing. 
Banyak faktor yang dipengaruhi atas berkembangnya teknologi saat ini, salah satunya bidang pendidikan. Mengingat bahwa pendidikan merupakan investasi besar bagi kemajuan suatu negara, maka lembaga Pendidikan dituntut agar bisa beradaptasi dengan perkembangan teknologi yang semakin cepat.

Pendidikan merupakan bentuk usaha dalam mencerdaskan kehidupan bangsa bahkan tercantum dalam pembukaan UUD 1945. Dengan demikian pemanfaatan teknologi yang optimal diharapkan dapat menjadi jembatan bagi guru dalam menyampaikan pesan pendidikan sehingga tujuan dari pendidikan dapat tercapai. Selain itu, dengan memanfaatkan multimedia diharapkan mampu menarik perhatian peserta didik terhadap pelajaran seperti matematika dan mengikis paradigma matematika yang tidak menyenangkan bahkan cenderung menakutkan. Pemanfaatan teknologi pada bidang pendidikan matematika dapat berupa pembelajaran penggunaan software matematika atau merancang dan membuatnya sendiri.

Rusman (Lukitawati, 2014) mengemukakan bahwa media pembelajaran merupakan alat bantu pembelajaran yang memiliki fungsi tersampaikannya pesan pembelajaran. Dengan demikian, media pembelajaran dapat dikatakan sebagai pembantu bagi guru dalam menyampaikan pembelajaran kepada siswa. Oleh karena itu, media pembelajaran berbasis ICT dapat digunakan guru dalam proses pembelajaran.

Munir (Ulfa, Yuanita, \& Roza, n.d.) mengemukakan bahwa ICT atau TIK (Teknologi Informasi dan Komunikasi) terdiri atas teknologi informasi yang berfungsi sebagai sistem pegolahan dan penyapaian informasi sehingga ICT atau TIK mampu menjadi alternatif pilihan untuk membantu pendidik sehingga pesan pendidikan tersampaikan dengan jelas.

Sedangkan menurut Hidayatulloh (2017) media pembelajaran berbasis teknologi layak dipertimbangkan sebagai alternatif pembelajaran mandiri yang dapat dimanfaatkan dalam proses pembelajaran di kelas maupun untuk belajar di rumah.

Arsyad (Andarwati \& Hernawati, 2013) menyatakan bahwa pembelajaran dengan komputer dapat mengasah berbagai latihan karena terdapat berbagai ilustrasi, animasi, dan grafik. Dengan demikian siswa disuguhkan pembelajaran dengan audio-visual yang jauh lebih menarik dibandingkan dengan hanya mendengarkan penjelasan guru di papan tulis.

Selanjutnya selain komputer aplikasi android merupakan alternatif yang cukup menarik dimana hampir seluruh siswa memiliki handphone(HP) berbasis android, berbeda dengan komputer atau notebook. Sebagai contoh, pada saat ini kota Bandung telah memiliki Edubox yang digunakan pada program SAKOJA (Sakola Juara). Edubox adalah server yang berisikan software aplikasi pembelajaran yang mudah dihubungkan dengan jaringan komputer baik melalui sambungan kabel (LAN) ataupun wireless (WLAN) sehingga dapat diakses siswa melalui handphone masing-masing. Sejauh ini Edubox di kota Bandung telah dimanfaatkan untuk pembelajaran paperless dari mulai pembelajaran harian sampai kegiatan tes kemampuan siswa melalui kuis, Penilaian Harian (PH), Penilaian Tengah Semester (PTS), Penilaian Akhir Semester (PAS), dan USBN-BK.

Pembelajaran berbasis android terlihat lebih praktis namun kenyataannya masih membutuhkan pengawasan lebih untuk menghindari penyalahgunaannya, sehingga pembelajaran dengan berbasis komputer lebih digemari. 
Dalam pengembangan media, guru memiliki peranan yang sangat penting untuk ikut mengembangkan media dan menyesuaikannya dengan metode, model, dan pendekatan pembelajaran yang digunakan. Selanjutnya dalam pembelajaran matematika berbasis komputer, guru dapat memanfaatkan berbagai aplikasi matematika seperti maple, mathlab, geogebra, cabri, geometri sketcpad dan lain sebagainya. Selain aplikasi-aplikasi tersebut, guru dapat membuatnya sendiri sesuai dengan strategi pembelajaran yang digunakan. Beberapa aplikasi tersebut diantaranya adobe flash, adobe animation, adobe dreamweaver, html 5 ataupun memanfaatkan Ms. Office seperti Microsoft Powerpoint, Excel, dan Word.

Pramita (Hasana \& Maharany, 2017) menyatakan bahwa permasalahan yang sering dihadapi oleh guru dalam membuat media adalah keterbatasan waktu serta kurangnya keterampilan yang dimiliki. Selanjutnya untuk mengsiasati permasalahan tersebut, guru dapat berkolaborasi dengan MGMP untuk membicarakan konsep media yang akan dibuat atau berkonsultasi dengan teknisi sekolah. Selain itu guru dapat menggunakan aplikasi yang mudah dipelajari dan praktis dalam penggunaannya. Marcovitz (Hasana \& Maharany, 2017) menyatakan bahwa produk pembelajaran menggunakan VBA Powerpoint bisa membuat tampilan powerpoint lebih menarik. Tampilan standar dari Powerpoint sendiri sebenarnya dapat menampilkan hasil yang menarik tergantung kreatifitas ketika menggunakannya. Namun dengan memanfaatkan VBA memungkinkan untuk memunculkan kreatifitas yang lebih kompleks dibandingkan dengan Powerpoint biasa.

Microsoft Powerpoint telah dikenal sebagai aplikasi untuk menampilkan presentesi yang menarik, namun belum banyak yang mengetahui bahwa dengan memanfaatkan VBA pada Ms.Powerpoint dapat membuat animasi diluar format yang tersedia di Ms.Powerpoint yang biasa digunakan. Lebih lanjut, tampilan atau animasi lain yang tidak terdapat sebelumnya dapat dibuat lebih menarik dengan membuat kode-kode program pada worksheet VBA bahkan dapat mengaplikasikan rumus-rumus matematika untuk menghasilkan sebuah animasi.

VBA merupakan aplikasi yang dikembangkan dalam sistem operasi Microsoft. Jika dibandingkan dengan bahasa pemograman seperti Java, C, C++, PHP, Python, ataupun ActionScript, bahasa pemograman pada VBA lebih mudah dipelajari. Berdasarkan uraianuraian diatas, peneliti tertarik untuk memanfaatkan VBA Powerpoint dalam pengembangan media pembelajaran pada materi SPLDV dengan tujuan menghasilkan media pembelajaran matematika yang valid, praktis, interaktif, dan menarik. Penelitian ini juga merupakan studi pendahuluan bagi penulis sebelum membuat penelitian untuk skripsi.

\section{METODE}

Bentuk penelitian ini penelitian dan pengembangan dengan model ADDIE yang dikembangkan oleh Robbert Maribe Branch (Hidayatulloh, 2017). ADDIE merupakan kepanjangan dari analysis (tahap analisis), design (tahap desain), development (tahap pengembangan), implementation (tahap penerapan), dan evaluation (tahap evaluasi). Sample pada penelitian ini adalah siswa kelas VIII disalah satu SMP Kota Bandung yang memiliki tingkat kecerdasan yang bervariasi. Uji coba dilakukan terhadap siswa dalam skala kecil.

Instrumen yang dipakai berupa angket. Angket terdiri atas angket ahli materi untuk menilai komponen Kelayakan Isi dan Komponen Penyajian. Selanjutnya angket ahli media untuk menilai aspek Software dan Aspek komunikasi audio visual, serta angket respon guru dan siswa terdiri atas sepuluh pernyataan untuk menilai respon terhadap media. 
Selanjutnya dilakukan analisis dari hasil angket sebagai berikut:

1. Analisis Data Kuantitatif (Ulfa, Yuanita, \& Roza, n.d.)

a. Analisis Data Hasil Angket Penilaian Validator

Penilaian validator menggunakan skala 1 sampai 4 yang disajikan pada berikut.

Tabel 1. Skala Penilaian Validator

\begin{tabular}{cc}
\hline Skala Penilaian & Kriteria \\
\hline 4 & Sangat Baik \\
\hline 3 & Baik \\
\hline 2 & Kurang \\
\hline 1 & Sangat Kurang \\
\hline
\end{tabular}

(Sudaryono, dkk. 2013)

Kemudian hasil angket validasi dianalisis dengan beberapa langkah yakni:

a) Menghitung rata-rata perolehan skor masing-masing aspek dengan rumus:

$\bar{x}=\frac{\sum x}{\text { banyakvalidator }}$

Keterangan :

$\bar{x} \quad=$ Rata - rata skor

$\sum x=$ Banyaknya skor tiap aspek

b) Mendeskripsikan perolehan data menjadi data kualitatif

Tabel 2. Tabel Konversi Skor Kualitatif

\begin{tabular}{cc}
\hline Rentang Skor & Kriteria \\
\hline $\bar{x}>\mathrm{Mi}+1,8 \mathrm{Sbi}$ & Sangat Baik \\
$\mathrm{Mi}+0,6 \mathrm{Sbi}<\bar{x} \leq \mathrm{Mi}+1,8 \mathrm{Sbi}$ & Baik \\
$\mathrm{Mi}-0,6 \mathrm{Sbi}<\bar{x} \leq \mathrm{Mi}+0,6 \mathrm{Sbi}$ & Kurang Baik \\
$\bar{x} \leq \mathrm{Mi}-0,6 \mathrm{Sbi}$ & Sangat Kurang Baik \\
\hline
\end{tabular}

(Eko Putro Widoyoko, 2009)

Pada penelitian ini, media pembelajaran dinyatakan valid apabila memenuhi kriteria minimal "Baik".

b. Analisis Data Respon Guru dan Siswa

Pada penelitian ini, media pembelajaran dinyatakan praktis apabila memenuhi kriteria minimal "Baik".

2. Analisis Data Kualitatif

Data kualitatif diperoleh dari masukkan atau tanggapan dari validator. Data-data tersebut dianalisis sesuai dengan data-data kuantitatif yang diperoleh dan dinyatakan dalam bentuk narasi.

\section{HASIL DAN PEMBAHASAN}

\section{Hasil}

Penelitian ini menghasilkan produk berupa media pembelajaran SPLDV yang dikemas dalam CD pembelajaran yang memuat aplikasi pembelajaran SPLDV berbasis VBA Powerpoint, tutorial cara penggunaan aplikasi dan profil peneliti. Media pembelajaran SPLDV ini berisi 
penyajian materi SPLDV dan latihan soalnya yang diatur secara sistematis agar mudah digunakan baik oleh guru maupun siswa.

Pengembangan media pembelajaran ini melalui tahap-tahap sebagai berikut :

1. Analysis (Tahap Analisis)
a. Analisis karakteristik dan kebutuhan siswa
b. Analisis kurikulum yang berlaku
c. Analisis teknologi
d. Analisis situasi

2. Design (Tahap Desain)

Tahap desain meliputi menyusun desain instrument dan menyusun desain media berbasis VBA Powerpoint.

\section{Development(Tahap Pengembangan)}

a) Pengembangan Instrumen

1) Lembar penilaian ahli materi

2) Lembar penilaian ahli media

3) Lembar kuisioner guru

4) Lembar kuisioner siswa

b) Pengembangan Media

Media pembelajaran ini dimulai dengan menu selamat datang pada halaman awal, kemudian pada halaman selanjutnya merupakan halaman utama. Berikut merupakan tampilan awal dan tampilan menu utama :

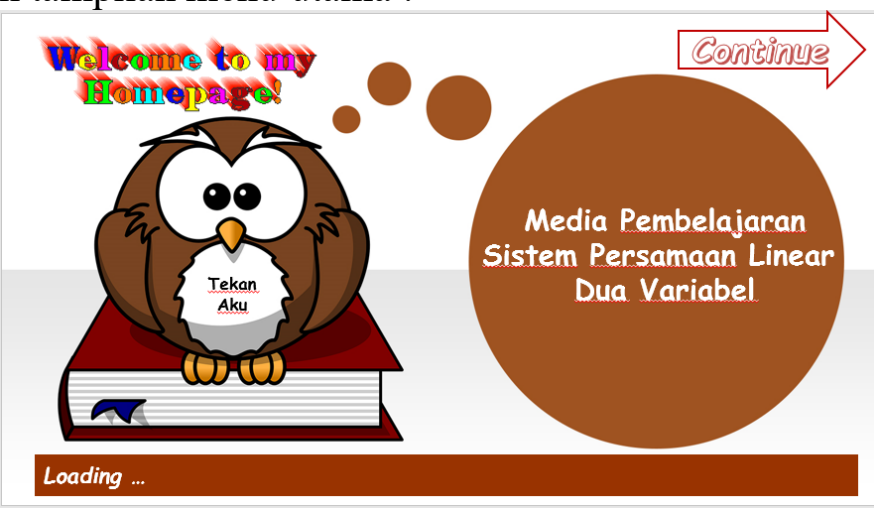

Gambar 1 Tampilan awal

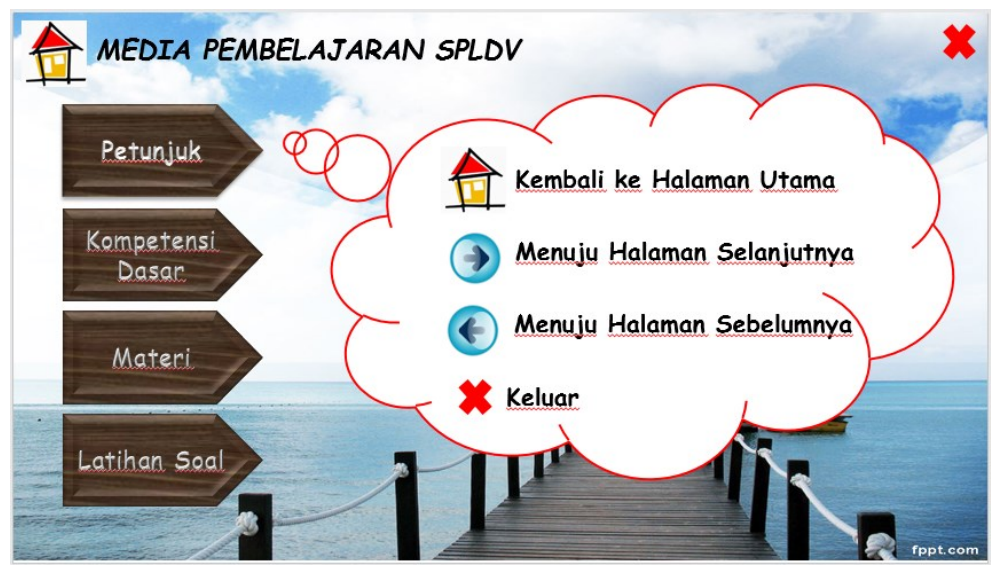

Gambar 2 Tampilan menu utama

Selanjutnya dari halaman utama, dapat terdapat menu yang dapat ditampilkan yaitu menu petunjuk, kompetensi dasar, Materi, dan Latihan Soal. 


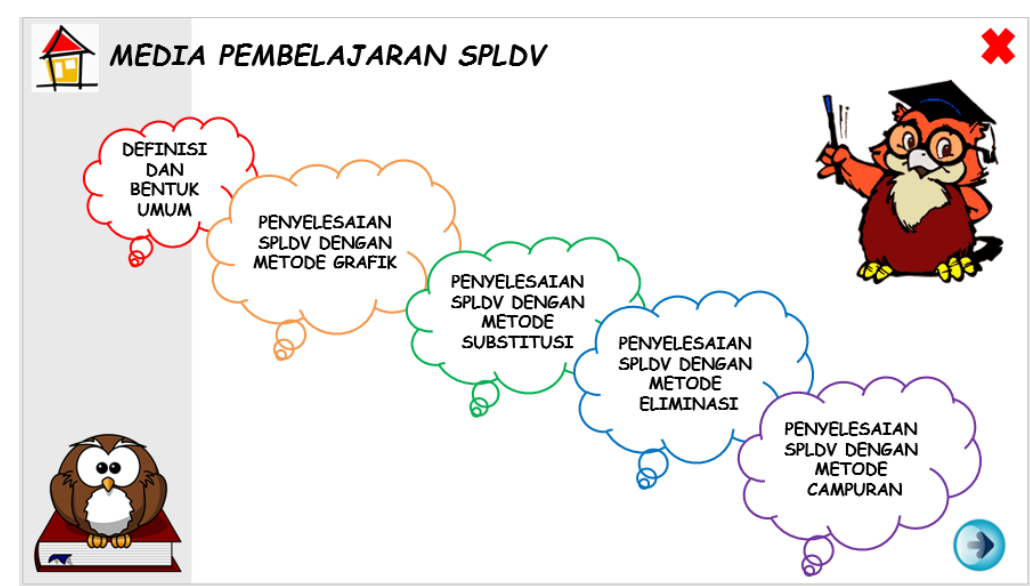

Gambar 3 Tampilan menu materi

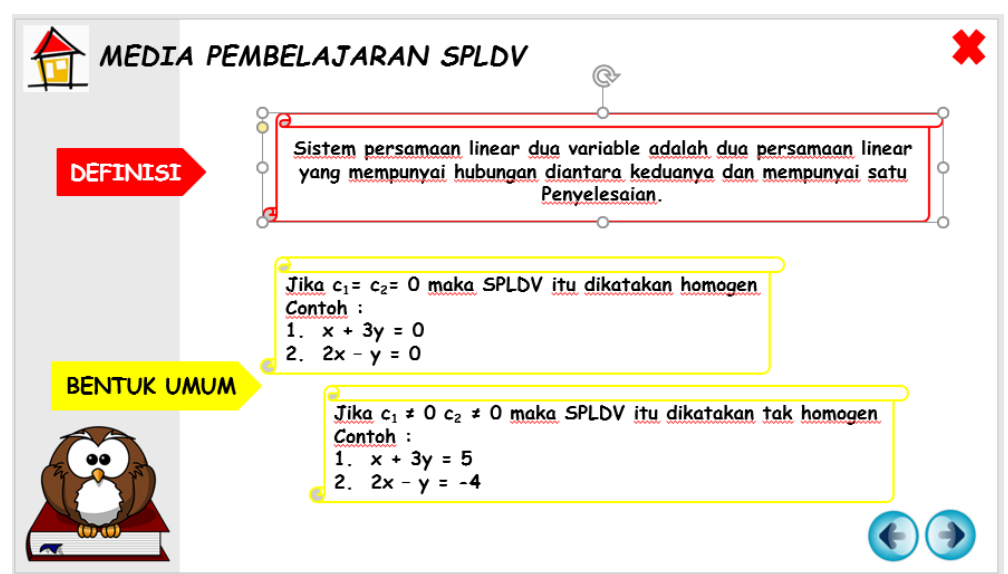

Gambar 4 Tampilan menu definisi dan bentuk umum

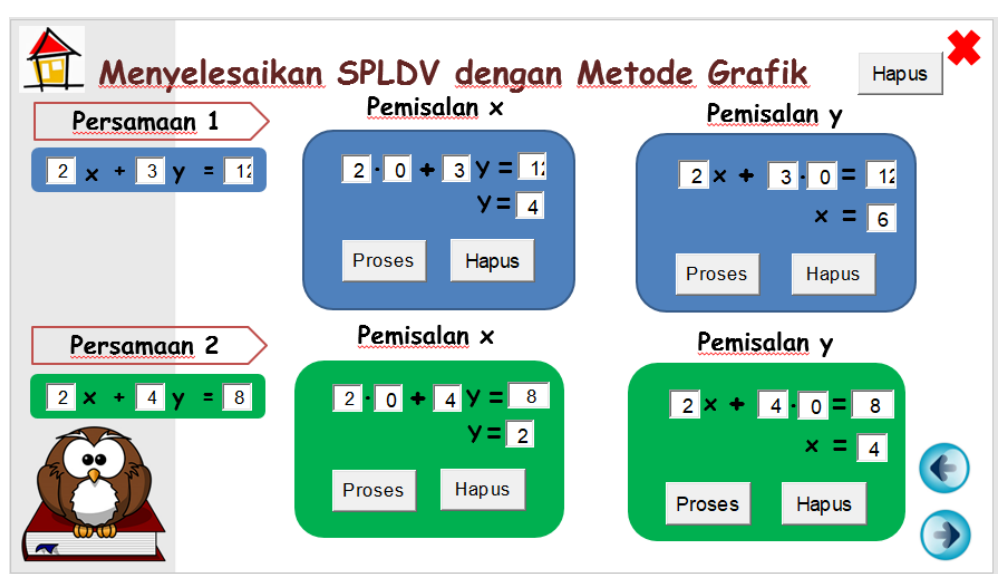

Gambar 5 Tampilan menu penyelesaian dengan metode grafik

Gambar 5 menunjukan tampilan langkah pertama dalam menyelesaikan SPLDV dengan metode grafik. Kotak yang berisi angka pada form persamaan 1 dan persamaan 2 dapat diganti kemudian angka pada form pemisalan $\mathrm{x}$ dan pemisalan $\mathrm{y}$ akan terisi setelah form persamaan diisi. Selanjutnya kotak lainnya diisi dengan pemisalan $\mathrm{x}$ dan $\mathrm{y}$ lalu tekan tombol proses untuk mengetahui nilai $\mathrm{x}$ dan $\mathrm{y}$ kemudian lanjutkan dengan menekan $\rightarrow$. 


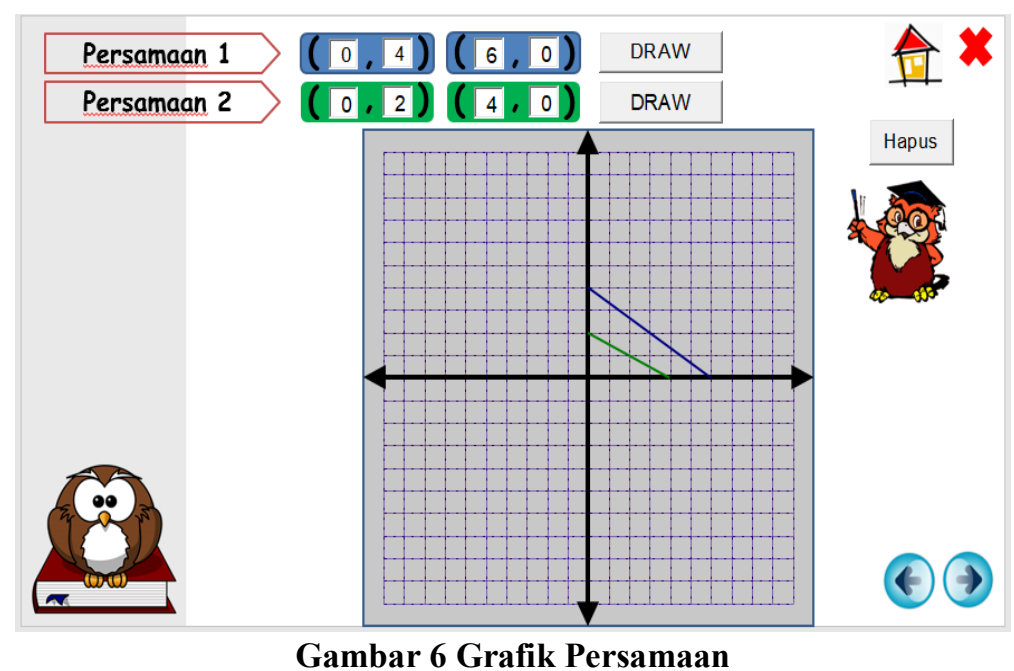

Gambar 6 merupakan proses lanjutan dari gambar 5. Angka koordinat diperoleh dari proses yang dilakukan sebelumnya. Setelah itu tekan tombol draw pada masingmasing persamaan maka terbentuklah grafik.

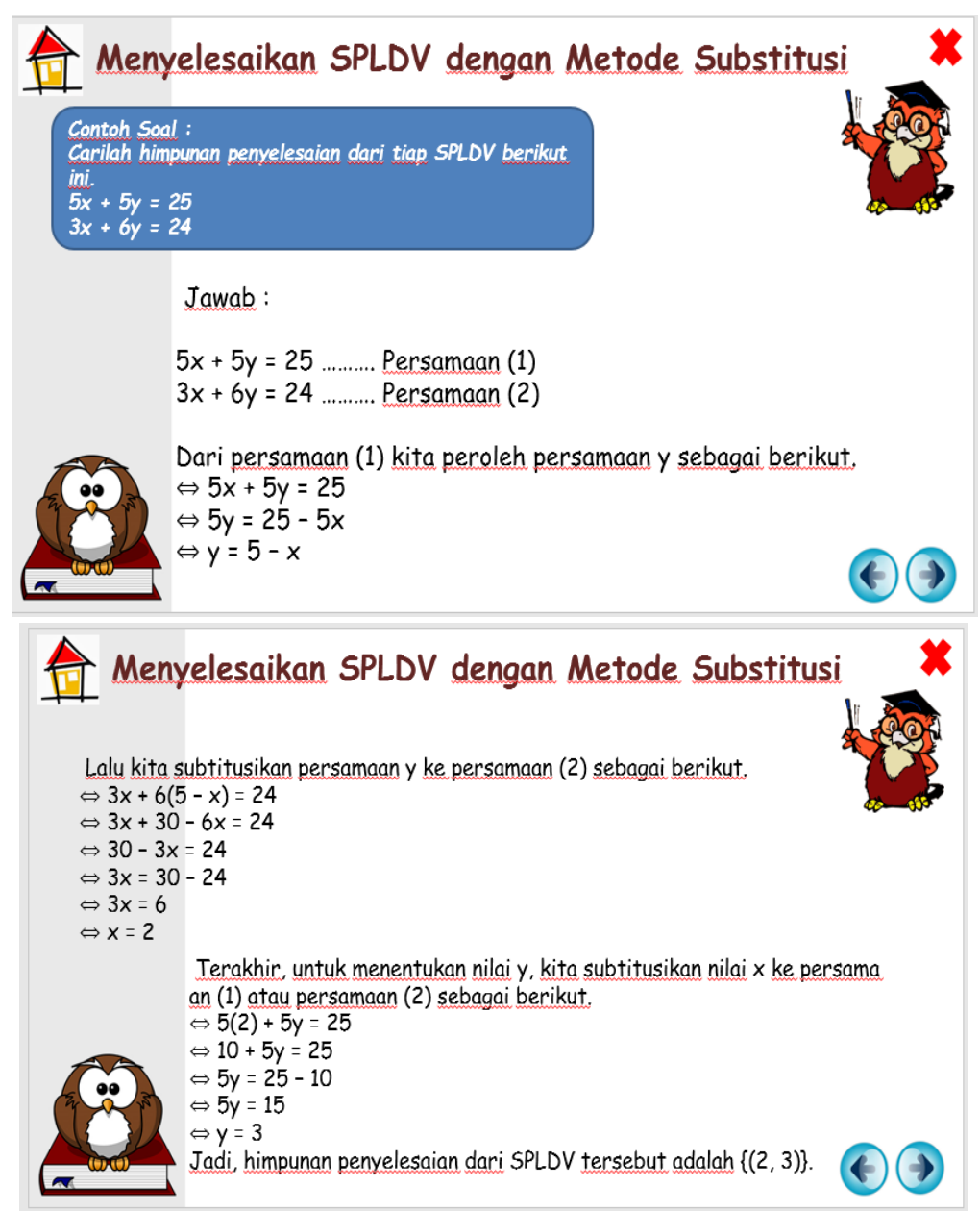

Gambar 7 Tampilan Penyelesaian dengan metode subtitusi 


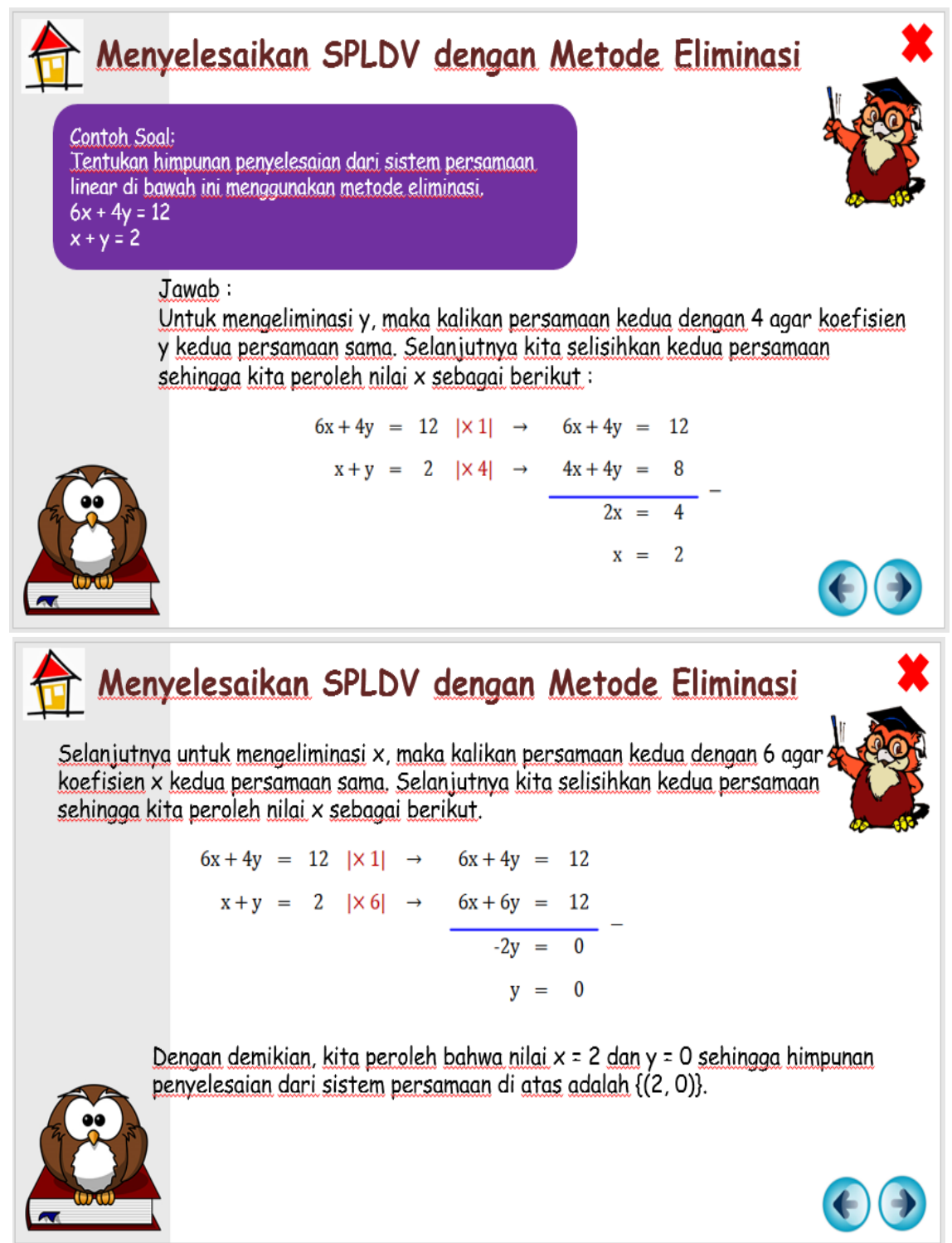

Gambar 8 Tampilan Penyelesaian dengan metode eliminasi

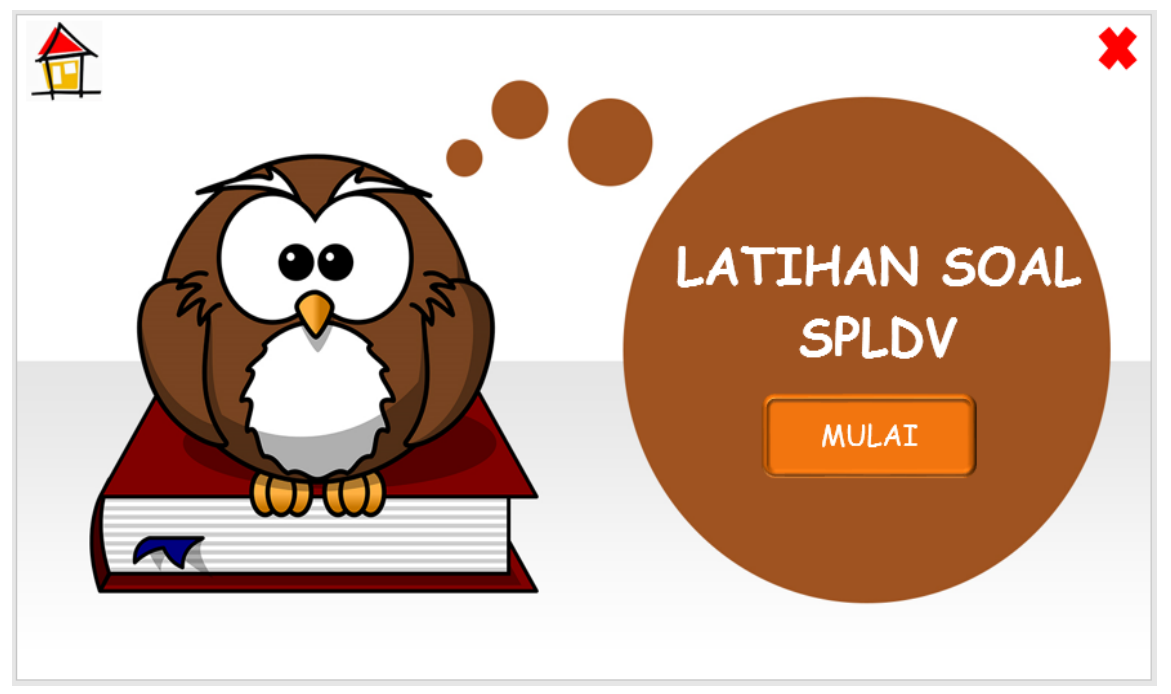

Gambar 9 Menu latihan soal 


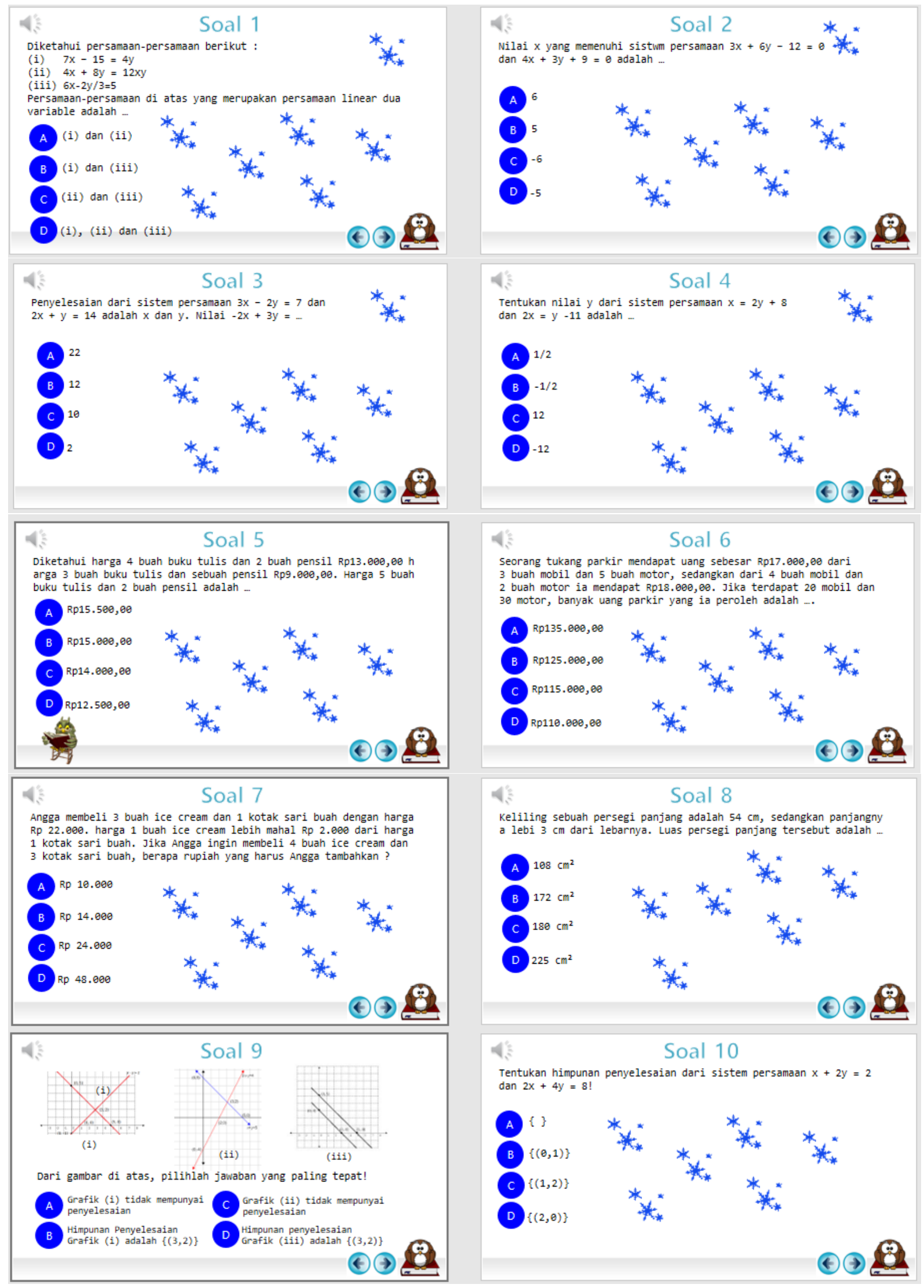

Gambar 10 Latihan soal 
Gambar 10 merupakan latihan soal. Pilih salah satu jawaban kemudian jika keluar kotak cek jawaban pilih yes jika sudah yakin dengan jawabannya dan tekan tombol no jika ingin memperbaikai jawaban lalu tekan tombol $\rightarrow$, dan kerjakan soal selanjutnya.

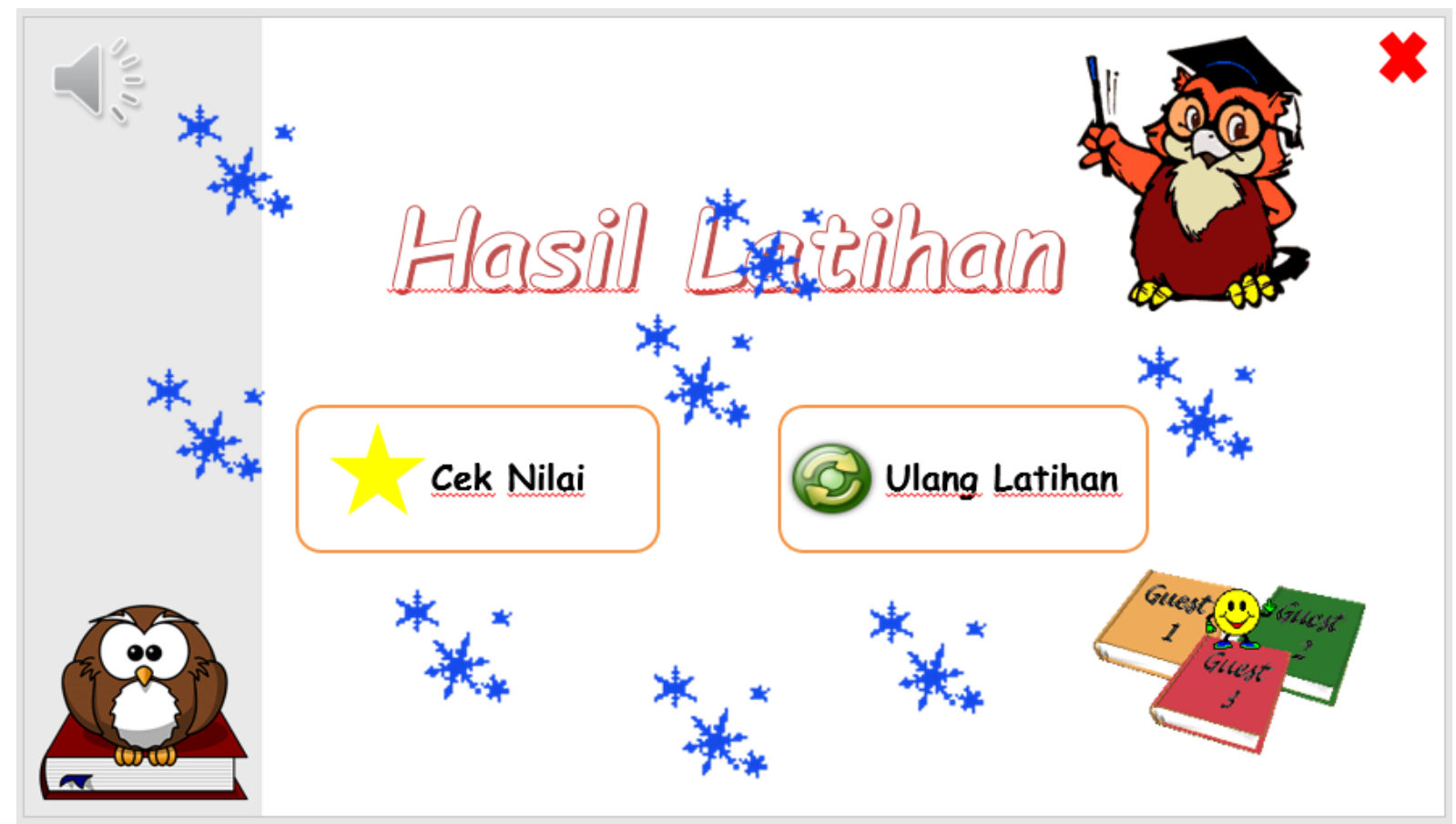

Gambar 11 Menu hasil latihan

\section{Implementation}

Tahap implementasi hanya dilakukan tahap implementasi awal.

\section{Evaluation (Evaluasi)}

Berikut ini merupakan hasil evaluasi media pembelajaran berbasis VBA Powerpoint.

a. Hasil Validasi Oleh Ahli Materi

Tabel 3. Hasil Validasi Oleh Ahli Materi

\begin{tabular}{lccc}
\hline \multicolumn{1}{c}{ Aspek yang dinilai } & \multicolumn{3}{c}{ Hasil Penelitian } \\
\cline { 2 - 4 } I. Komponen Kelayakan Isi & Validator 1 & Validator 2 & Rata-rata \\
$\begin{array}{l}\text { A. Kecukupan Materi } \\
\text { B. Keterkaitan komopetensi }\end{array}$ & 4 & 3 & 3,5 \\
$\quad \begin{array}{l}\text { inti/ kompetensi dasar } \\
\text { C. Akurasi Materi }\end{array}$ & 4 & 4 & 4 \\
$\begin{array}{l}\text { II. Komponen Penyajian } \\
\text { A. Penyajian Pembelajaran }\end{array}$ & 3,6 & 3,5 & 3,75 \\
$\begin{array}{l}\text { B. Komunikatif dan Interaktif } \\
\text { C. Aspek Bahasa }\end{array}$ & 3,5 & 3,6 & 3,6 \\
\hline \multicolumn{2}{c}{ Rata-rata } \\
\hline
\end{tabular}




\section{b. Hasil Validasi Oleh Ahli Media}

Tabel 4. Hasil Validasi Oleh Ahli Media

\begin{tabular}{lccc}
\hline \multicolumn{1}{c}{ Aspek yang dinilai } & Validator & Validator & Rata-Rata \\
\hline A. Aspek Software & $\mathbf{1}$ & $\mathbf{2}$ & (3,2 \\
B. Aspek komunikasi audio visual & 3 & 3 & 3,1 \\
C. Aspek lainnya & 3,25 & 2,4 & 2,7 \\
\hline \multicolumn{2}{c}{ Rata-Rata } & 3,5 & 3,37 \\
\hline
\end{tabular}

\section{c. Hasil Respon Guru dan Siswa}

Tabel 5. Hasil Respon Guru dan Siswa

\begin{tabular}{cc}
\hline Responden & Rata-Rata Skor \\
\hline Guru & 3,50 \\
Siswa & 3,18 \\
\hline
\end{tabular}

\section{Pembahasan}

Pembuatan media pembelajaran ini memanfaatkan aplikasi Ms.Powerpoint yaitu Visual Basic Application. Dalam pembuatannya selain memanfaatkan animasi biasa pada Powerpoint, media pembelajaran dengan VBA Powerpoint ini juga diberikan bahasa pemrograman agar penampilan dan fungsinya lebih efektif, efisien, unik dan juga menarik. Selanjutnya untuk mengetahui validitas dari Media Pembelajaran Berbasis VBA Powerpoint ini, dilakukan evaluasi dengan cara memberikan angket terhadap Ahli Materi sebanyak dua orang, Ahli Media sebanyak dua orang, seorang guru dan lima siswa.

Berdasarkan hasil evaluasi dari ahli materi, ahli media, angket respon guru dan siswa diperoleh hasil skor rata-rata sebagai berikut, validari dari ahli materi sebesar 3.64 (sangat valid) menunjukan bahwa materi yang disajikan dalam media sudah memenuhi aspek kelayakan isi dan komponen penyajian dengan kriteria sangat baik. Kemudian validasi dari ahli media sebesar 3.06 (valid) menunjukan media pembelajaran yang dihasilkan telah memenuhi kriteria baik dalam aspek rekayasa perangkat lunak, aspek komunikasi audiovisual, dan aspek lainnya. Hasil analsisi respon guru sebesar 3.50 (sangat valid) menunjukan bahwa media tersebut memenuhi kriteria sangat baik. Selanjutnya hasil analisis respon siswa sebesar 3.18 (valid) menunjukan bahwa media pembelajaran memenuhi kriteria baik. Dengan demikian hasil secara keseluruhan menunjukan skor rata-rata sebesar 3.34 dan dinyatakan valid sehingga dapat disimpulkan bahwa media pembelajaran SPLDV ini berada pada kategori baik dan dapat digunakan dalam proses pembelajaran atau untuk menunjang penelitian lainnya.

Penelitian ini merupakan penelitian awal, maka dalam penelitian selanjutnya media ini diharapkan dapat dijadikan sebagai alat bantu dalam meningkatkan kemampuan siswa baik itu kemampuan kognitif maupun kemampuan afektif. Hal ini diperkuat oleh beberapa penelitian dengan memanfaatkan VBA dalam penelitiannya diantaranya:

1. Suwastarini, Dantes, \& Candiasa (2015) dalam penelitiananya tentang pengaruh implementasi berbasis media TIK terhadap motivasi dan hasil belajar matematika siswa SLB B (Tunarungu). Hasil dari penelitian tersebut adalah implementasi pembelajaran berbasis TIK berpengaruh signifikan terhadap motivasi belajar siswa dengan nilai t-test $>$ 
t-tabel yaitu $30.262>2.179$ dan terhadap hasil belajar siswa dengan nilai t-test $>$ t-tabel yaitu $20.107>2.179$.

2. Setiawan (2016) dalam penelitiannya mengenai efektifitas pembelajaran berbasis animasi dalam meningkatkan minat belajar matematika siswa. Hasil dari penelitian tersebut adalah penggunaan media berbasis animasi efektif dalam meningkatkan minat belajar matematika siswa. Hal ini ditunjukan dari hasil t-hitung sebesar 4.225 sedangkan t-tabel sebesar 2.058.

3. Bernard \& Chotimah (2018) dalam penelitiannya untuk meningkatkan kemampuan penalaran matematika siswa dengan pendekatan Open-Ended menggunakan VBA Powerpoint. Berdasarkan hasil penelitian tersebut, disimpulkan bahwa pembelajaran dengan pendekatan Open-Ended menggunakan VBA Powerpoint lebih baik dibandingkan dengan kelas yang menggunakan pembelajaran biasa. Hal ini ditunjukan dari hasil t-test sebesar 3.3692 dan sig. 0.000 kurang dari 0.05 artinya ada perbedaan nilai rata-rata NGain antara kelas eksperimen dan kelas kontrol. Rata-rata N-Gain kelas eksperimen sebesar 0.456 artinya lebih tinggi dari rata-rata N-Gain kelas kontrol sebesar 0.332 .

4. Rohaeti, Bernard \& Novtiar (2019) dalam penelitiannya untuk meningkatkan kemampuan penalaran siswa SMP dengan pengembangan media VBA dengan pendekatan OpenEnded. Hasil dari penelitian tersebut adalah terdapat pengaruh media pembelajaran VBA Powerpoint dan Excel dalam meningkatkan kemampuan penalaran siswa dibandingkan dengan sebelum menggunakan media. Hal ini ditunjukan dengan hasil uji t-sample berpasangan yang memperoleh nilai signifikan sebesar $0.000<0.05$.

Dengan demikian sangat memungkinkan bagi penulis untuk melanjutkan penelitian ini ke tahap selanjutnya. Penelitian tersebut dapat berupa penelitian untuk meningkatkan kemampuan kognitif siswa atau kemampuan afektif siswa dengan bantuan media pembelajaran berbasis VBA Powepoint.

\section{KESIMPULAN}

Berdasarkan penelitian ini maka kesimpulannya adalah media pembelajaran berbasis VBA Powerpoint pada materi SPLDV untuk siswa SMP kelas VIII dinyatakan valid dan dapat dipakai untuk menunjang kegiatan pembelajaran materi SPLDV disamping model pembelajaran dan pendekatan yang diterapkan oleh guru. Selanjutnya media pembelajaran ini dapat dimodifikasi ataupun dikembangkan untuk menghasilkan media yang unik, menarik, dan interaktif sesuai kebutuhan.

\section{UCAPAN TERIMA KASIH}

Penulis mengucapkan terimakasih kepada pihak yang terkait demi kelangsungan penelitian ini. Termasuk didalamnya ibu Luvy Sylviana Zanthy, S.P., M.Pd. karena dukungan dan bimbingannya dalam menyelesaikan penelitian ini. Tak lupa kepada pihak SMP yang dijadikan tempat berlangsungnya penelitian.

\section{DAFTAR PUSTAKA}

Andarwati, D., \& Hernawati, K. (2013). P - 22 Pengembangan Lembar Kegiatan Siswa ( Lks ) Berbantuangeogebra Untuk Membelajarkan. Prosiding, 978-979.

Bernard, M., \& Chotimah, S. (2018). Improve student mathematical reasoning ability with 
open-ended approach using VBA for powerpoint. AIP Conference Proceedings, 2014(September). https://doi.org/10.1063/1.5054417

Hasana, S. N., \& Maharany, E. R. (2017). Pengembangan Multimedia Menggunakan Visual Basic For Application (Vba) Untuk Meningkatkan Profesionalisme Guru Matematika. Jurnal Pendidikan Matematika Dan IPA, 8(2), 60-69. Retrieved from http://jurnal.untan.ac.id/index.php/PMP/article/view/21178/17224

Hidayatulloh, M. (2017). Pengembangan Media Pembelajaran Menggunakan Software Adobe Flash Pada Pokok Bahasan Barisan Dan Deret Kelas XII SMA Negeri 16 Makasar. (Skripsi). Fakultas Tarbiyah dan Keguruan UIN Alauddin, Makassar.

Lukitawati, P. (2014). Pengembangan Media Pembelajaran Matematika Berbasis ICT ( Information And Communication Technology) Melalui Pendekatan SAVI ( Somatic, Auditory, Visual, and Intelectual ) Pada Materi Geometri Transformasi Kelas VII di SMP Ma'had Islam Pekalongan. Delta, 42-50.

Rohaeti, E. E., Bernard, M., \& Novtiar, C. (2019). Pengembangan Media Visual Basic Application untuk Meningkatkan Kemampuan Penalaran Siswa SMP dengan Pendekatan Open-Ended. 3(2), 95-108.

Setiawan, I., Ilmu, F., Dan, T., Islam, U., \& Mataram, N. (2017). EFEKTIFITAS MEDIA PEMBELAJARAN BERBASIS ANIMASI SISWA KELAS VII MTS NURUL ULUM MERTAK TOMBOK.

Suwastarini, N. N. (2015). Pengaruh Implementasi Pembelajaran Berbasis Media Teknologi Informasi dan Komunikasi terhadap Motivasi dan Hasil Belajar siswa SDLB B (Tuna Rungu) pada SLB B Negeri PTN Jimbaran. E-Journal PPS Universtas Pendidikan Ganesha Prodi Studi Penelitian Dan Evaluasi Pendidikan, 5(1), 1-10.

Ulfa, Y. L., Yuanita, P., \& Roza, Y. (n.d.). PENGEMBANGAN MEDIA PEMBELAJARAN MATEMATIKA BERBASIS ICT PADA POKOK BAHASAN LINGKARAN UNTUK SISWA KELAS VIII SMP / MTS BERBASIS ICT PADA POKOK BAHASAN LINGKARAN UNTUK SISWA KELAS VIII SMP / MTS, 1-10. 
414 Rosmayanti \& Zanthy,. Pengembangan Media Pembelajaran Berbasis Visual Basic App... 